\title{
Direitos humanos da paciente criança
}

\author{
Child patient's human rights \\ Derechos humanos del paciente niño
}

Kalline Eler ${ }^{1}$

Aline Albuquerque ${ }^{2}$

\begin{abstract}
Resumo
Objetivo: analisar os direitos da criança no campo dos cuidados em saúde a partir da aplicação do referencial dos direitos humanos dos pacientes. Metodologia: baseia-se em pesquisa teórica e normativa, fundamentada no levantamento, sistematização e análise de artigos científicos sobre os cuidados em saúde das crianças e dos comentários gerais elaborados pelo Comitê para os Direitos da Criança. Resultados: o referencial dos direitos humanos do paciente, aplicado à criança, assegura o direito à participação, informação e privacidade, influenciando o processo de tomada de decisões no âmbito dos cuidados em saúde. Conclusão: no âmbito do direito internacional dos direitos humanos, a criança é sujeito de direitos e, na esfera dos cuidados em saúde, esses direitos lhe asseguram um papel central.
\end{abstract}

Palavras-chave: Criança. Pacientes. Bioética. Direitos humanos.

\begin{abstract}
Objective: analyze the rights of the child in the field of health care based on the application of the human rights framework of patients. Methodology: This research was based on the survey, systematization and analysis of scientific studies on children's health care and on the General Comments prepared by the Committee on the Rights of the Child. Results: the patient's human rights, applied to the child, ensures the right to participation, information and privacy, influencing the decision-making process in health care. Conclusion: in the context of international human rights law, children are subject to rights and, in the field of health care, these rights assure them a central role.
\end{abstract}

Keywords: Child. Patients. Bioethics. Human rights.

\section{Resumen}

Objetivo: analizar los derechos del niño en el campo de la atención sanitaria a partir de la aplicación del referencial de los derechos humanos de los pacientes. Metodología: se basa en la investigación teórica y normativa, fundamentada en el levantamiento, sistematización y análisis de artículos científicos sobre los cuidados en salud de los niños y de los comentarios generales elaborados por el Comité para los Derechos del Niño. Resultados: los derechos humanos de los pacientes, aplicados al niño, garantizan la participación, la información y la privacidad, influyen en el proceso de toma de decisiones en el cuidado de la salud. Conclusión: El niño, en el marco del derecho internacional de

\footnotetext{
${ }^{1}$ Professora de Direito Civil da Universidade Federal de Juiz de Fora/Campus Governador Valadares. Doutoranda em Bioética pela Universidade de Brasília/Cátedra Unesco. E-mail: kallinecarvalho@hotmail.com

2 Professora de Bioética e Direitos Humanos do Programa de Pós-graduação em Bioética da UnB. E-mail: alineaoliveira@hotmail.com
} 
los derechos humanos, es sujeto de derechos y, en el ámbito de la asistencia sanitaria, estos derechos le garantizan un papel central.

Palabras-Ilave: Niño. Pacientes. Bioética. Derechos humanos.

\section{Introdução}

O reconhecimento da criança enquanto sujeito de direitos deu-se, no cenário internacional, a partir da Convenção sobre os Direitos da Criança (CDC), de 1989 (1). A adoção da CDC pela Assembleia da Organização das Nações Unidas (ONU) foi precedida de longos debates que buscaram conciliar as diferentes visões dos Estados sobre a infância e, ao mesmo tempo, estabelecer um rol amplo de direitos que traduzisse uma perspectiva centrada na criança. Assim, a CDC previu, pela primeira vez no direito internacional dos direitos humanos, a criança enquanto sujeito de direitos, modificando a percepção segundo a qual as crianças seriam objeto de proteção e propriedade dos seus genitores.

A CDC introduz uma perspectiva centrada na criança, abrangendo uma gama de direitos civis e políticos (artigos 13, 14, 15, por exemplo), e direitos econômicos, sociais e culturais (artigos 24, 26, 27, por exemplo). No entanto, a despeito dessa ampla previsão de direitos, verifica-se que, no âmbito dos cuidados em saúde, as crianças ainda ocupam papel secundário, estando largamente excluídas das interações entre seus genitores e os profissionais de saúde (2) (3). Assim, não obstante a afirmação da criança como sujeito de direitos no plano jurídico, seu reconhecimento enquanto tal no contexto dos cuidados em saúde não se efetivou, em consequência, seus direitos, principalmente aqueles que lhe asseguram um papel ativo, continuam sendo rotineiramente desrespeitados (4) (3).

Tendo em vista que os direitos previstos na CDC devem ser observados em todos os âmbitos da vida da criança, este artigo objetiva analisar os direitos da criança no campo dos cuidados em saúde a partir da aplicação do referencial dos direitos humanos dos pacientes (DHP).

Enquanto ramo do direito internacional dos direitos humanos, os DHP referem-se à aplicação dos direitos humanos a todos os indivíduos submetidos a cuidados em saúde (5). Esse referencial abarca os instrumentos normativos no âmbito internacional, tais como convenções, pactos e declarações em matéria de direitos humanos; e a jurisprudencial internacional constituída pelas decisões dos órgãos de monitoramento dos direitos humanos da ONU e dos Sistemas Europeu, Interamericano e Africano dos Direitos 
Humanos. Os DHP incluem uma série de direitos no âmbito dos cuidados em saúde, sendo o seu núcleo formado pelo direito à vida; direito a não ser submetido à tortura nem a penas ou tratamentos cruéis, desumanos ou degradantes; direito ao respeito pela vida privada; direito à liberdade e à segurança pessoal; direito à informação; direito de não ser discriminado e direito à saúde (6). Não insertos na lógica do direito consumerista, esses direitos estão presentes no contexto de vivência do paciente em cuidados ofertados pelos sistemas de saúde, público ou privado, e independentemente da natureza jurídica da relação travada com o profissional de saúde. Assim, os DHP também se aplicam às crianças que, sendo reconhecidas como sujeitos de direito, titularizam direitos específicos no âmbito dos cuidados em saúde.

O referencial dos DHP se apresenta como o mais adequado para a proteção dos pacientes, pois, além de impor ao Estado as responsabilidades de respeitar, proteger e realizar, parte de uma visão ampliada de serviços de saúde, não se restringindo ao acesso aos bens ou aos serviços de saúde. A ênfase é colocada no cuidado que significa zelar pela autonomia, segurança, privacidade, entre outros bens éticos essenciais para se alcançar melhores resultados em saúde e o incremento do bem-estar do paciente.

Os DHP se assentam em uma visão holística do paciente que ultrapassa o modelo biomédico de saúde focado apenas na enfermidade (6), buscando compatibilizar o reconhecimento da vulnerabilidade acrescida do paciente com os deveres ético-jurídicos de respeito à autonomia pessoal e sua promoção. No que tange aos grupos populacionais com vulnerabilidade particularmente acrescida como, por exemplo, crianças, pessoas idosas e pessoas com deficiência, os DHP instituem que as responsabilidades oriundas do reconhecimento da vulnerabilidade devem vir acompanhadas da obrigação de promover a autonomia dos sujeitos envolvidos.

Nesse sentido, destaca-se que a criança, embora vulnerável em virtude da sua maturidade em desenvolvimento, também é detentora de direitos humanos. Assim, as crianças representam um dos grupos populacionais que mais enfrentam obstáculos para exercer seus direitos e, por essa razão o presente artigo tem como escopo analisar os direitos humanos da criança enquanto paciente, sob a ótica do referencial teóriconormativo dos DHP, de modo a concorrer para a alteração da vigente cultura nos serviços de saúde de mitigação da participação da criança e de desconsideração de sua vontade e preferências no processo terapêutico. 
Dentre os direitos humanos da criança, enquanto paciente, serão analisados apenas os direitos à participação, à informação e à privacidade. Justifica-se a escolha em razão de serem os direitos mais recorrentes no cotidiano dos cuidados em saúde, revelando-se, dessa forma, importantes para a promoção do cuidado centrado na criança e da sua autonomia. Sob o prisma metodológico, trata-se de pesquisa de cunho teórico e documental, fundamentada em estudos desenvolvidos no campo dos direitos humanos, versando especificamente sobre as peculiaridades dos direitos das crianças no âmbito dos cuidados em saúde. Dentre esses estudos, destacam-se as pesquisas coordenadas por Coyne (2) (3): estudos empíricos que reforçam a importância do envolvimento da criança no projeto terapêutico.

A pesquisa também se sustenta em dois comentários gerais, um elaborado pelo Comitê para os Direitos da Criança sobre o direito à participação (7) e outro editado pelo Comitê de Direitos Humanos da ONU sobre o direito à privacidade (8). A adoção desses documentos justifica-se, pois os Comitês constituem órgão de direitos humanos e são responsáveis por oferecer uma melhor compreensão dos conteúdos de direitos humanos e das suas implicações para os Estados, partes interessadas, organizações não governamentais e a sociedade em geral.

O presente artigo estrutura-se em três partes, cada uma dedicada a examinar os direitos acima mencionados. Inicialmente, são apresentados os conteúdos dos direitos de forma ampla, sem referência específica ao seu contexto de aplicação, para, em um segundo momento, analisar como se dará a aplicação aos cuidados em saúde da criança de forma aprofundada.

Esclarece-se, por fim, que por criança, compreende-se os menores de 18 anos conforme a definição de empregada pela CDC em seu primeiro artigo.

\section{Direito à participação}

O artigo 12 da CDC (1) institui uma norma sem precedentes em um tratado de direitos humanos, ao apontar para a condição jurídica da criança que, por um lado, não tem a plena capacidade do adulto, mas, por outro, é sujeito de direitos. O parágrafo primeiro garante a todas as crianças que estão em condições de formular seus próprios juízos o direito de se expressar livremente sobre todos os assuntos relacionados a ela; 
ainda dispõe que tais opiniões devem ser consideradas, em função da idade e da maturidade da criança.

O artigo 12 não apenas estabelece o direito da criança de opinar sobre todos os assuntos que a afetam, mas também institui um valor fundamental que serve de vetor interpretativo para os demais direitos consagrados na $C D C$, que não podem ser desfrutados de modo integral se não respeitarem a criança enquanto sujeito com opiniões próprias (7).

A participação coloca em relevo que a inclusão das crianças na tomada de decisão deve ser um processo: amigável, de modo que as crianças se sintam seguras e confortáveis para externar suas opiniões; seguro e sensível para reduzir ao mínimo o risco de que as crianças sofram violência, exploração ou outras consequências negativas; responsável, no sentido de que as crianças têm o direito de receber um retorno acerca da forma com a qual sua participação influenciou no resultado (7); transparente e informativo; voluntário, não podendo a criança ser obrigada a expressar sua opinião; e relevante, ou seja, as questões a respeito das quais as crianças expressam suas opiniões devem ter pertinência autêntica para suas vidas.

Para a aplicação correta do artigo 12, os Estados devem adotar cinco medidas: a) preparação: os responsáveis por escutar a criança devem assegurar que ela foi informada sobre o direito de expressar sua opinião e a opção de comunicá-la diretamente ou através de um representante. Assim, o responsável deve preparar a criança antes que ela seja escutada, explicando-Ihe como, quando e onde será escutada e quem serão os ouvintes; b) audiência: o contexto em que a criança exerce o seu direito de ser ouvida deve ser propício para inspirar-Ihe confiança, de modo que ela sinta que o adulto responsável por ouvi-la está realmente disposto a considerar seriamente o que ela decidir comunicar; c) avaliação da capacidade: os Estados devem estabelecer práticas apropriadas para examinar a capacidade da criança; d) comunicação dos resultados: a criança deve ser informada do resultado do processo e acerca da forma com a qual sua opinião foi levada em consideração. A comunicação dos resultados à criança é uma garantia de que suas opiniões não foram escutadas apenas como mera formalidade e, ainda, pode estimular a criança a confirmar o que foi considerado, mostrando-se de acordo com o resultado, recusando ou apresentando uma nova proposta; e) reclamação, recursos e reparação: a 
legislação interna dos Estados deve prever procedimentos de denúncia e instrumentos de recursos para a hipótese do direito à participação da criança ser violado (7).

O Comentário Geral no 12 (7) explicita que os Estados não devem partir da premissa de que a criança é incapaz de expressar seu ponto de vista, antes devem pressupor que ela tem capacidade para formar suas próprias opiniões. Isso significa que a criança não precisa, primeiramente, comprovar que é detentora dessa capacidade.

O artigo 12 do CDC, por sua vez, não impõe qualquer limite de idade ao direito de a criança expressar sua opinião e o Comitê desencoraja os Estados a introduzirem, por lei ou na prática, limites de idade que restrinjam o direito da criança de ser ouvida em todos os assuntos que a afetam. A idade em si não é fator determinante para indicar se a opinião da criança será tomada em consideração, pois, como acentua o Comitê, os níveis de compreensão das crianças não estão ligados de maneira uniforme a sua idade biológica. Há estudos que demonstram que a informação, a experiência, o ambiente, as expectativas sociais e culturais e o nível de apoio contribuem para o desenvolvimento da capacidade da criança para formar uma opinião. Por isso, as opiniões da criança devem ser avaliadas mediante o exame do caso concreto, conforme sua maturidade. Por maturidade, o Comitê entende a habilidade de compreender e avaliar as consequências de um determinado assunto, ou seja, refere-se à habilidade da criança para expressar suas opiniões sobre os assuntos de maneira razoável e independente, não sendo exigida profundidade de compreensão. A criança não precisa ter um conhecimento exaustivo de todos os aspectos do assunto que a afeta, mas precisa ter uma compreensão que seja suficiente para formar adequadamente um juízo sobre o assunto (7).

A esse respeito, o Comitê sublinha que existem estudos demonstrando que a criança é capaz de formar opiniões desde muito cedo, mesmo quando ainda não consegue expressá-las verbalmente. Por essa razão, ressalta que a aplicação do artigo 12 requer o reconhecimento e o respeito de formas não-verbais de comunicação, como a brincadeira, a expressão corporal e facial, o desenho e a pintura, por meio das quais as crianças demonstram a capacidade de compreender, escolher e ter preferências.

O direito à participação nos cuidados em saúde abarca o direito de ser ouvido, de ter sua percepção, vontade e preferências respeitadas, em suma, ser verdadeiramente envolvido na tomada de decisão acerca dos assuntos afetos ao seu corpo e a sua saúde. No entanto, como demonstra Coyne (2) (3), diversos estudos conduzidos com crianças 
hospitalizadas têm indicado que elas são largamente excluídas das interações entre seus genitores e os profissionais de saúde, bem como não são envolvidas no planejamento ou nas decisões relativas aos seus cuidados e, mesmo quando expressam um desejo de envolvimento, não recebem suporte para concretizá-lo. A maioria das crianças, nas pesquisas apontadas pela autora, ocupa uma posição marginal e passiva nas consultas, sendo as informações direcionadas aos genitores em detrimento da criança. As crianças são ignoradas e desacreditadas pelos profissionais de saúde, e sua participação é desestimulada e prejudicada por fatores que incluem: medo de causar problemas fazendo perguntas; falta de tempo e dificuldade que elas encontram para entrar em contato com os profissionais de saúde; desconhecimento de quem são os profissionais responsáveis pelo tratamento; dificuldade para entender a terminologia médica; e atitudes dos pais que interrompiam ou mudavam as respostas dos seus filhos, impedindo um comportamento mais ativo. Segundo Coyne (3), os principais fatores de obstrução da participação das crianças submetidas a tratamento clínico são: os estilos de comunicação; os comportamentos dos adultos, principalmente dos profissionais de saúde; e o estado da doença que pode gerar uma apatia em relação ao entorno. Os adultos, diante desse fato, deveriam receber educação e treinamento sobre como facilitar a participação das crianças por meio, por exemplo, do treinamento para aprimorar a comunicação.

Em outra pesquisa coordenada por Coyne (2) a fim de avaliar a participação das crianças submetidas a tratamento de câncer em um hospital pediátrico da Irlanda, constatou-se que as principais decisões, ou seja, aquelas que se referiam às investigações, à decisão de tratar, à administração das terapias, à seleção dos protocolos e procedimentos de tratamento, foram tomadas em sua grande maioria pelos profissionais de saúde e apenas discutidas com os genitores. Dessa forma, a participação das crianças limitou-se às decisões secundárias referentes ao modo como os cuidados e os procedimentos seriam realizados, sem qualquer impacto no resultado do tratamento escolhido. Nos resultados da pesquisa, crianças entre sete e 11 anos ficaram satisfeitas com o nível de tomada de decisão a elas conferido, contudo, os adolescentes, a partir dos 12 anos de idade, expressaram descontentamento com a limitação do seu papel nos seus cuidados em saúde. Para eles, um envolvimento real significaria receber informações; expressar e ter suas preferências consideradas; assim como negociar e escolher os tratamentos que serão ministrados. 
Observa-se que as oportunidades de participação das crianças nos seus cuidados, normalmente, são bastante limitadas e que os genitores e os profissionais de saúde não consideram, em geral, as muitas maneiras pelas quais as crianças podem ser envolvidas (2) (3) (9). Torna-se extremamente difícil para uma criança adotar uma postura mais participativa em seus cuidados quando os profissionais ainda permanecem com uma visão paternalista. Por essa razão, Olszewski e Goldkind (10) sustentam que a inclusão das crianças na tomada de decisão em saúde, conforme a sua capacidade e o interesse em fazê-lo, deve ser a posição padrão para garantir que elas sejam rotineiramente ouvidas nas consultas e quanto aos tratamentos a que são submetidas.

A realização do direito da criança de expressar suas opiniões e fazer escolhas requer que sejam informadas sobre a decisão a ser tomada, as opções e as possíveis decisões que podem ser adotadas, bem como suas consequências (7). Assim, o direito à informação, objeto do item subsequente, revela-se essencial, posto ser condição imprescindível para o exercício efetivo do direito à participação.

\section{Direito à informação}

As crianças devem receber as informações sobre os tratamentos propostos, seus efeitos e resultados, de maneira apropriada e acessível, para que possam ser efetivamente incluídas no processo de tomada de decisão dos seus cuidados em saúde. O Comitê para os Direitos da Criança, como ressaltado, recomenda que o processo de decisão no qual a criança participa seja transparente e informativo, ou seja, deve-se dar a criança informação completa, acessível, atenta às suas condições de vida e apropriada a sua idade (7).

$O$ direito à informação configura pré-requisito essencial para que haja autonomia, sendo um direito do paciente e um dever do profissional de saúde, que é obrigado a empenhar esforços contínuos para transmitir ao paciente todos os aspectos envolvidos em seus cuidados em saúde.

O direito à informação, nos cuidados em saúde, tem como parâmetro o paciente. A informação deve ser ofertada de forma abrangente, transparente e isenta de viés, não sendo aquela que o corpo médico acredita ser favorável ao tratamento e sim aquela que o paciente considera importante (11). Observa-se uma mudança de perspectiva, pois esse direito não se restringe a ser informado de acordo com aquilo que os profissionais de saúde julgam apropriado. Os pacientes não são recipientes passivos daquilo que o corpo 
de profissionais considera como seu melhor interesse, ao contrário, devem receber as informações para tomar uma decisão acerca das opções de cuidado. Sendo assim, a comunicação do profissional de saúde deve ser feita, primeiramente, à criança, que é o paciente submetido aos cuidados em saúde. Não se deve utilizar uma linguagem autoritária, mas um tom de conversa em que à criança é conferida a oportunidade de dialogar e trazer seus questionamentos, dúvidas e preferências.

A divulgação transparente e sensível para as crianças das informações sobre sua doença diminui a ansiedade, aumenta a autoestima, promove o senso de autocontrole e encoraja a criança a aderir ao tratamento proposto (12). Assim, compartilhar informações com a criança que está doente e aprender sobre suas expectativas e medos pode fornecer, aos genitores e profissionais de saúde, percepções valiosas sobre o que a doença significa para a criança, como a está processando e o que é mais importante para ela enquanto indivíduo e naquele momento. Tratando-se de tratamento continuado, as informações poderão ser reduzidas em pequenas doses ao longo do tempo, permitindo uma melhor absorção do conteúdo (12).

O direito à informação não se coaduna com a exacerbação de informações técnicas que dificultam a compreensão do que é mais importante para a tomada de decisão. O respeito a esse direito também se relaciona com as habilidades de comunicação do profissional de saúde que, ao apresentar as informações, deve estar atento às necessidades do paciente, compartilhando os conteúdos de uma maneira que a criança possa compreender. Devido à natureza fiduciária da relação, o profissional de saúde tem o dever de disponibilizar ao paciente as informações que melhor se ajustam ao seu contexto particular. Essa abordagem não apenas endossa o direito à informação, mas também assegura a qualidade dos cuidados em saúde.

Em virtude da dificuldade que algumas crianças encontram para expressar suas preferências e vontades, torna-se necessário um pouco de conhecimento de psicologia infantil para que a comunicação seja efetiva. Por meio de uma linguagem adequada, devese fornecer à criança uma descrição da sua condição de saúde e das opções disponíveis de cuidado, bem como dos benefícios e encargos esperados de determinado tratamento.

A compreensão das informações pela criança também faz parte do conteúdo do direito à informação, de modo que o profissional de saúde precisa empregar esforços para 
que a criança entenda claramente os riscos materiais concernentes a determinado tratamento.

No âmbito do direito à informação, uma questão revela-se interessante: a exceção terapêutica que permite ao profissional de saúde reter informações quando sua divulgação tiver o risco de causar danos ao paciente. A exceção terapêutica remonta a uma concepção paternalista da relação médico-paciente e foi prevista, em 1847, no primeiro Código de Ética da Associação Médica Americana que estabelecia o "dever sagrado do médico de evitar qualquer coisa que viesse a desencorajar o paciente e deprimir seu espírito". Na prática contemporânea, todavia, a tradição paternalista foi substituída pelo respeito à autonomia do paciente, de modo que a tomada de decisão sobre cuidados em saúde é resultado da relação de parceria entre o profissional de saúde e o paciente, o que se aplica também à criança. Nesse sentido, os profissionais são obrigados a divulgar amplamente as informações para que a criança possa participar significativamente dos seus cuidados.

Ao contrário do que pode indicar o senso comum, inúmeras pesquisas citadas por Fleischman (12) têm demonstrado que a divulgação das informações para a criança sobre a sua condição diminui a ansiedade, mesmo quando se trata de cuidados de fim de vida. Além disso, tendo em vista que a maioria dos profissionais de saúde não está na melhor posição para analisar os efeitos psicológicos causados pela divulgação das informações na saúde da criança, o recurso à exceção terapêutica só poderia ser aceito em situações bastante peculiares, baseada em razões convincentes relativas ao bem-estar de uma criança em particular e não fundamentada em motivos amplos como, por exemplo, a eventual ansiedade que a informação possa causar, a idade do paciente, o tipo de doença ou a visão do profissional sobre o risco mínimo, etc. (13) (14).

O escopo da exceção terapêutica ainda permanece indefinido nas cortes do Reino Unido, por exemplo, mas tem-se advertido que esse privilégio não pode ser invocado, genericamente, em função da idade da criança, para impedir que ela seja esclarecida sobre sua saúde (13); ao contrário, o compartilhamento das informações deve ser considerado essencial para incrementar o processo de envolvimento da criança nos seus cuidados. Quando o paciente é o parâmetro, há uma abordagem mais extensa do direito à informação; seu contorno é estabelecido, não pelo que o profissional de saúde considera aconselhável ou benéfico informar ao paciente, mas pelo o que o paciente considera 
importante para tomar uma decisão. Isso é válido para a criança que tem o direito de receber as informações sobre o seu estado de saúde de uma maneira apropriada para, então, manifestar sua opinião sobre as opções de tratamento disponíveis. Assim, o reconhecimento da maturidade em desenvolvimento da criança é suficiente para garantir o direito de ser informado sobre seu estado de saúde. A revelação das informações, além de promover a capacidade da criança para tomar decisões sobre cuidados em saúde, aumenta sua confiança nos profissionais envolvidos em seus cuidados.

No relacionamento com a criança enquanto paciente e com seus genitores, os profissionais de saúde devem tentar alcançar um acordo sobre o modo e o tipo de informação que será compartilhada, presumindo que informações cruciais para a tomada de decisão serão sempre fornecidas de forma clara e transparente. A comunicação aberta e honesta afeta positivamente a relação familiar, na maioria dos casos, e previne os sentimentos de raiva e traição que podem surgir na criança que recebe a informação sobre seu estado de saúde apenas tardiamente (12) (15).

$O$ direito à informação revela-se fundamental, especialmente nas situações de doenças crônicas ou terminativas. Crianças que não tiveram a oportunidade de entender a própria doença sentem-se mais angustiadas, pois, além de não terem abertura para discutir seus sentimentos, imaginam que a doença é tão grave que ninguém é capaz de Ihes falar a verdade; são internadas com maior frequência e apresentam um aumento nos sintomas de depressão. Essas crianças estão frequentemente preocupadas com a dor e o abandono, apresentam uma consciência da morte que não será explicitada, a menos que sejam encorajadas a falar sobre isso, e ficam imaginando como suas famílias irão lidar com sua morte (12) (15). Por outro lado, consoante as pesquisas apontadas por Fleischman (12) e Harrison (15), as crianças que recebem informação e são educadas sobre sua condição de saúde conseguem desempenhar melhor um papel ativo nos seus cuidados, maximizando seu bem-estar. Segundo Harrison (15), várias pesquisas confirmam que a maioria das crianças com câncer, quando questionada se gostaria de ser informada, respondeu afirmativamente, mesmo que o conteúdo da informação versasse sobre a piora no seu estado de saúde e morte iminente. A autora afirma, ainda, com base em pesquisas, que a maioria das crianças com doenças terminais sabe que está prestes a morrer e que os pais que conseguiram falar sobre a morte com a criança não se arrependeram, ao contrário dos pais que não conversaram sobre esse assunto. 
Ainda que os pais demonstrem o desejo de proteger seu filho, escondendo informações que acreditam ser angustiantes, avassaladoras ou prejudiciais, os profissionais de saúde têm o dever de conscientizá-los que esse tipo de atitude pode ser mais prejudicial e contrário ao melhor interesse da criança. Honrar seu desejo de proteção pode gerar um isolamento da criança, pois não terá o suporte de cuidadores para poder discutir seus medos e ansiedades. Por essa razão, os profissionais devem tentar elaborar, juntamente com os pais, um plano estratégico de divulgação das informações que esteja de acordo com a perspectiva da criança em tratamento.

Os profissionais de saúde, em razão do seu conhecimento especializado, figuram em uma posição privilegiada quando se trata de calcular os riscos das várias opções de tratamentos e cirurgias, mas não estão em posição de decidir acerca da quantidade de informação necessária para viabilizar o exercício da autodeterminação do paciente, o que configura um dos aspectos do direito à privacidade, apresentado a seguir.

\section{Direito à privacidade}

O direito à privacidade está previsto em vários tratados internacionais de direitos humano ${ }^{3}$ e instrumentos internacionais não vinculativos, como a Declaração da Associação Médica Mundial sobre os Direitos do Paciente. Sob a ótica do direito humano à privacidade, o paciente tem o direito de conduzir sua própria vida, concretizar juízos de valor e escolhas existenciais sem interferências e imposições. O Estado, enquanto garantidor dos direitos humanos, deverá zelar e adotar medidas legislativas e outras para assegurar tal direito (8).

No âmbito dos cuidados em saúde, essa abordagem é bastante ampla e traduz-se no direito de recusar cuidados, o que abrange o direito de não realizar exames, testes ou procedimentos terapêuticos; direito de buscar outras opiniões médicas; direito de ter tempo suficiente para tomar decisões, salvo em situações de emergência; e direito de ter suas diretivas antecipadas respeitadas pelos familiares e médicos. O respeito pela vida privada também implica o direito de ter suas escolhas quanto à visita e ao exame do seu corpo pelos profissionais de saúde (6).

\footnotetext{
${ }^{3}$ Artigo 17 (1), do Pacto Internacional dos Direitos Civis e Políticos; Artigo 16 (1) da Convenção sobre Direitos da Criança; Artigo 22, da Convenção sobre os Direitos das Pessoas com Deficiência.
} 
$\mathrm{O}$ direito à privacidade, enquanto direito de manter o controle sobre as próprias informações, abrange o direito de saber, de forma clara, quais informações estão sendo utilizadas, para quais propósitos, para quem serão divulgadas. O paciente, portanto, tem direito de acesso ao seu prontuário e, após acessá-lo, tem o direito de solicitar que sejam excluídas informações ou corrigidas quaisquer imprecisões (16).

O direito à privacidade não é absoluto, estando justificada sua flexibilização em razão da proteção da saúde pública, como, por exemplo, nos casos de doenças altamente infecciosas e de notificação compulsória; de direitos e liberdades de terceiros; ou da prevenção da ocorrência de crime. Contudo, até mesmo o afastamento desse direito deve ser proporcional, mínimo e restrito ao alcance desses objetivos (6). O Comitê de Direitos Humanos da ONU recomenda que os Estados editem leis para regulamentar as hipóteses de interferências na vida privada, detalhando de modo preciso as circunstâncias nas quais podem ser autorizadas, e ainda orienta para que essas intervenções ocorram apenas se o conhecimento das informações privadas for essencial para a consecução de interesse coletivo (8).

No que concerne às crianças, o direito ao respeito pela vida privada encontra correspondência na $\operatorname{CDC}(1)$, no artigo 16, segundo o qual "nenhuma criança será objeto de interferência arbitrárias ou ilegais em sua vida particular, sua família, seu domicílio, ou sua correspondência, nem de atentados ilegais a sua honra e a sua reputação" e no artigo $40(2, \mathrm{VI})$ que assegura o respeito a sua vida privada durante todas as fases do processo em que esteja sendo julgada por infração à lei penal do país.

No que tange à privacidade relacionada à confidencialidade das informações pessoais do paciente, observa-se, pela literatura consultada, que não há maiores dificuldades em reconhecer que informações sanitárias das crianças sejam mantidas de modo confidencial. A grande questão diz respeito ao dever de confidencialidade em relação aos pais ou responsáveis legais, isto é, até que idade ou em quais circunstâncias os profissionais de saúde podem revelar aos pais as informações confidenciais da criança (17).

A temática do direito à confidencialidade da criança foi suscitada no ano de 1986 , quando a Suprema Corte inglesa precisou decidir sobre o caso de uma mãe chamada Victoria Gillick. A decisão proferida no caso foi no sentido de que os médicos, agindo no melhor interesse da criança, poderiam prescrever contraceptivos se a criança fosse 
competente e consentisse para tanto. Isso seria possível, independentemente da vontade dos pais em prol do direito da criança com competência Gillick à privacidade, sendo este direito o mesmo dos adultos (17).

No direito britânico, crianças maiores de 16 anos presumem-se juridicamente capazes e, portanto, estão sujeitas às mesmas normas que os adultos quanto à confidencialidade. Aos menores de 16 anos, que satisfazem o teste da competência Gillick, também é assegurado o direito à confidencialidade e, nesse sentido, podem consentir sobre tratamentos, independentemente do consentimento dos pais, que sequer precisam ser informados sobre a decisão. Eventual divulgação caracterizaria quebra do direito da criança à confidencialidade. Ressalta-se que, para decidir sobre a competência Gillick, junto com a análise da habilidade decisional da criança, os médicos envolvidos no cuidado irão analisar se essa decisão também atende aos seus melhores interesses.

O Comitê para os Direitos da Criança recomenda aos Estados que introduzam leis ou regulamentos para garantir o acesso das crianças a assessoramento e aconselhamento médico confidencial, sem o consentimento dos pais, independentemente da idade da criança, nos casos em que sejam necessários para a proteção da sua segurança ou bemestar, especialmente quando tenham experimentado violência e maus-tratos e em matéria de saúde sexual e reprodutiva. O direito de receber aconselhamento é independente ao direito a outorgar consentimento médico e, por isso, não se submete à limitação etária (7).

O direito ao respeito pela vida privada compreende igualmente o direito de consentir quanto a qualquer tipo de tratamento. O consentimento informado no campo dos direitos humanos sedimenta-se no Relatório do Relator Especial sobre Direito à Saúde, publicado em 2009, que o define como sendo uma decisão voluntária e suficientemente informada capaz de promover autodeterminação, integridade física e bem-estar do paciente (6). O consentimento informado é a concretização do respeito da autonomia do paciente para decidir sobre aquilo que Ihes é mais íntimo: o corpo. Esse documento registra como deve ser o encontro do paciente com o profissional de saúde: não se reduzindo a mera assinatura de um documento contendo informações técnicas de difícil compreensão, ao contrário, implica comunicação, diálogo franco com informações que sejam capazes de esclarecer o paciente acerca dos diferentes elementos envolvidos no seu tratamento. Os instrumentos utilizados para fins de consentimento deverão, portanto, conter informações acessíveis e claras sobre todos os aspectos envolvidos. 
O referencial dos DHP aplicado aos cuidados em saúde da criança, ao enfatizar um modelo de cuidado centrado no paciente, assegura o seu direito à privacidade, conferindoIhe voz para externar suas preferências. Diante disso, não obstante o consentimento das crianças seja um dos temas mais controversos, seu direito de influenciar o processo de tomada de decisão, como um dos aspectos do direito à privacidade, permanece válido.

\section{Conclusão}

Este estudo demonstrou que, no âmbito do direito internacional dos direitos humanos, a criança é sujeito de direitos e, na esfera dos cuidados em saúde, esses direitos the asseguram um papel central. Assim, sob o enfoque dos DHP, a criança é reconhecida como protagonista dos seus cuidados, sendo dotada de direitos específicos, compatíveis com o reconhecimento da sua vulnerabilidade acrescida e o dever éticojurídico de protegê-la. A vulnerabilidade específica da criança, portanto, não pode ser utilizada como argumento para impedir seu engajamento nos cuidados em saúde. Diante disso, não é aceitável que os profissionais de saúde continuem desconsiderando as obrigações oriundas das normas de direitos humanos que concedem à criança a faculdade de participar ativamente dos seus cuidados. Reconhece-se no Brasil a escassez de conteúdos de direitos humanos na formação dos profissionais de saúde, em consequência, avanços notórios no campo dos direitos humanos das crianças não foram incorporados nos serviços de saúde. Diante disso, registra-se a necessidade de se reconfigurar a formação na área da saúde a fim de que o profissional se perceba como um agente importante na promoção dos direitos da criança. Ademais, no cuidado em saúde da criança, a assimetria da relação entre profissional de saúde e paciente é maior, o que acentua o poder do primeiro, e dificulta o exercício de direitos por parte da criança. Assim, as crianças se deparam com óbices mais sólidos para exercer seus direitos, pois, além de não serem devidamente informadas, se encontram sujeitas a condutas paternalistas e autoritárias de profissionais de saúde. Sublinha-se, como demonstrado neste trabalho, que os pais e os profissionais de saúde são os principais responsáveis por obstar o engajamento da criança nos cuidados, concorrendo para seu desinteresse quanto ao seu tratamento.

Por fim, enfatiza-se que o reconhecimento da criança enquanto protagonista do seu cuidado em saúde, além de ser compatível com as determinações de direitos humanos, tem o condão de aumentar sua satisfação em relação ao tratamento escolhido, sua 
confiança no profissional de saúde e no sistema em geral. Também produz resultados positivos para o tratamento, aumentando a aderência e o bem-estar da criança, e reduzindo efeitos adversos e ansiedades.

\section{Referências}

1. ONU. Convenção sobre os Direitos da Criança. 1989

2. Coyne I, Amory A, Kiernan G, Gibson F. Children's participation in shared decisionmaking: Children, adolescents, parents and healthcare professionals' perspectives and experiences. Eur J Oncol Nurs. Elsevier Ltd; 2014;18(3):273-80.

3. Coyne I. Children's participation in consultations and decision-making at health service level: a review of the literature. Int J Nurs Stud. Elsevier; 2008 Nov;45(11):1682-9.

4. Grootens-Wiegers P, Hein I, Staphorst M. Using Children's Voice to Optimize Pediatric Participation in Medical Decision Making. Am J Bioeth [Internet]. 2018 Mar 4 [cited 2018 May 4];18(3):14-6.

5. Cohen J, Ezer T. Human Rights in patient care: A theoretical and practical framework. Health Hum Rights. 2013;15(2):7-19.

6. Albuquerque A. Direitos Humanos dos Pacientes. Curitiba: Juruá; 2016. 288 p.

7. ONU. General Comment $n^{\circ} 12$. The right of the child to be heard [Internet]. Commitee on the Rights of the Child; 2009.

8. ONU. Comentário Geral n 16: Artigo 17 - Direito À Privacidade. 1988.

9. Gabe J, Olumide G, Bury M. It takes three to tango: a framework for understanding patient partnership in pediatric clinics. Soc Sci Med. 2004 Sep;59(5):1071-9.

10. Olszewski AE, Goldkind SF. The Default Position: Optimizing Pediatric Participation in Medical Decision Making. Am J Bioeth. 2018 Mar;18(3):4-9.

11. Spatz ES, Krumholz HM, Moulton BW. The new era of informed consent: Getting to a reasonable-patient standard through shared decision making. Jama. 2016;6-7.

12. Fleischman A. Pediatric Ethics. New York: Oxford: University Press; 2016. 243 p.

13. Brazier M, Cave E. Medicine, Patients and The Law. Manchester: Manchester University Press; 2016. 618 p.

14. Brazier M, Lobjoit M. Protecting the vulnerable: Autonomy and consent in health care. New York: Routledge; 2014. 196 p. 
15. Harrison C. Truth telling in pediatric: What they don't know might hurt them. In: Miller G, editor. Pediatric Bioethics. New York: Cambridge University Press; 2009. p. 73-86.

16. Hagger $L$. The child as vulnerable patient: protection and empowerment. Farnham: Ashgate; 2009. 252 p.

17. Herring J. Medical law. New York: Oxford: University Press; 2011. 307 p.

Como citar esse artigo:

Eler K, Albuquerque A. Direitos humanos da paciente criança. Cadernos Ibero-Americanos de Direito Sanitário. 2019 jan./mar.; 8(1): 36-52. 